\title{
Demonstratives, Definite Descriptions and
}

\author{
Non-redundancy*
}

\author{
Kyle Blumberg ${ }^{\dagger}$
}

\begin{abstract}
In some sentences, demonstratives can be substituted with definite descriptions without any change in meaning. In light of this, many have maintained that demonstratives are just a type of definite description. However, several theorists have drawn attention to a range of cases where definite descriptions are acceptable, but their demonstrative counterparts are not. Some have tried to account for this data by appealing to presupposition. I argue that such presuppositional approaches are problematic, and present a pragmatic account of the target contrasts. On this approach, demonstratives take two arguments and generally require that the first, covert argument is non-redundant with respect to the second, overt argument. I derive this condition through an economy principle discussed by Schlenker (2005).
\end{abstract}

\section{Introduction}

Conventional semantics for demonstratives maintain that they are devices of 'direct reference', and that demonstratives refer to specific individuals or objects. ${ }^{1}$

This theory is motivated by cases such as the following:

(1) [Pointing at Pete] That man plays tennis.

*Forthcoming in Philosophical Studies.

${ }^{\dagger}$ khb251@nyu.edu

${ }^{1}$ See, e.g., (Kaplan, 1989). 
On the direct reference approach, the demonstrative in (1) acts like a name and refers to the individual that I'm pointing at, namely Pete. Since (1) does seem to mean the same as 'Pete plays tennis', examples such as this do appear to support the direct reference semantics.

However, assuming that 'that' is not ambiguous, several theorists have observed that there are other uses of demonstratives that make trouble for this simple picture:

(2) [Pointing to a copy of On Denoting] That man was a genius.

(3) Mary talked to no senator without declaring afterwards that that senator was the one who would sponsor her bill (Elbourne, 2008, 445).

(4) Every father dreads that moment when his oldest child leaves home (King, 2001, 10).

(5) Every man who owns a donkey beats that donkey (Elbourne, 2008, 446).

In (2), the speaker gestures towards an article but intends to talk about its author. This is a case of so-called "deferred ostension". Still more problematic are (3)-(5): in none of these cases is the demonstrative referring to a particular object. In (3) the whole demonstrative is bound by a higher quantifier, and in (4) the pronoun in the matrix of the demonstrative is being bound by a quantifier outside of it (a so-called "quantifying in" use). Meanwhile, the demonstrative in (5) takes a "donkey anaphoric" reading. ${ }^{2}$

Theorists have tried to construct unified accounts of demonstratives that are able to accommodate all of (1)-(5). One popular approach is to treat demonstratives as a certain type of definite description. To illustrate, on such approaches (2) and (4) are roughly equivalent to (6) and (7), respectively:

\footnotetext{
${ }^{2}$ See (Nowak, 2014) for a good discussion of non-deictic uses of demonstratives and the threat they pose to the direct reference approach. Also see $\S 5.3$ for further discussion of donkey anaphoric demonstratives.
} 
(6) The man who wrote the book I'm pointing to was a genius.

(7) Every father dreads the moment when his oldest child leaves home.

These descriptivist paraphrases do seem to mean the same as the original sentences.

However, an important challenge for descriptivists is how they account for cases where $\ulcorner$ that $F\urcorner$ and $\ulcorner$ the $F\urcorner$ are not interchangeable. There are two types of case to consider. First, when demonstratives are acceptable but their definite counterparts are not. Suppose I think that Plato was smarter than Aristotle. Standing in front of The School of Athens I say:

(8) (a) That man [pointing to Plato] was a lot smarter than that man [pointing to Aristotle].

(b) ?? The man [pointing to Plato] was a lot smarter than ?? the man [pointing to Aristotle]. ${ }^{3}$

Although ( $8 \mathrm{a})$ is acceptable, $(8 \mathrm{~b})$ is not. This is surprising if demonstratives are just definite descriptions.

The second type of case involves sentences where descriptions are acceptable but their demonstrative counterparts are not. Consider the following minimal pairs:

(9) (a) The author of Blood Meridian also wrote The Road.

(b) ?? That author of Blood Meridian also wrote The Road [adapted from (Nowak, 2014, 427)]. ${ }^{4}$

(10) [We're doing a head-count of all of the students on a particular floor of our building, and we walk into a classroom.]

\footnotetext{
${ }^{3}$ King (2001) discusses contrasts like this. This particular case is inspired by King (2001, 71-72).

${ }^{4}$ Wolter (2006) and Nowak (2018) discuss similar contrasts.
} 
(a) The only student is Mike.

(b) ?? That only student is Mike. ${ }^{5}$

(11) [We are at a horse race, and have just seen Money Pony win]

(a) The fastest horse won the race.

(b) ?? That fastest horse won the race. ${ }^{6}$

(12) [We have just heard that an important boxing match has just concluded, though we do not know who the participants were.]

(a) The winner will receive a lot of money.

(b) ?? That winner will receive a lot of money.

Although the (a) sentence in each pair is acceptable, the (b) sentence is not. What these cases seem to show is that, unlike definite descriptions, a demonstrative $\ulcorner$ that $F\urcorner$ is unacceptable when $F$ is known to apply to exactly one individual in context. Once again, this contrast is surprising if demonstratives are just disguised definite descriptions.

There is, then, the following challenge for theories of demonstratives: they must explain how demonstratives can sometimes be virtually semantically equivalent to definite descriptions (as in (4)), but also how the meaning of $\ulcorner$ that $F\urcorner$ and $\ulcorner$ the $F\urcorner$ can come apart (as in (8a)-(8b) and (9a)-(9b)). In this paper, I focus on cases where descriptions are acceptable but their demonstrative counterparts are not, and in particular on contrasts exhibited by pairs such as (9a)-(9 b). ${ }^{7}$ I try to explain these contrasts from within a broadly descriptivist

\footnotetext{
${ }^{5}$ As far as I am aware, this contrast has not been discussed before. This is particularly striking given how much attention has been paid to the contrast between 'the only' and 'an only' (Herdan \& Sharvit, 2006; Coppock \& Beaver, 2015).

${ }^{6}$ Wolter (2006), Hawthorne \& Manley (2012) and Nowak (2014, 2018) also discuss contrasts involving superlatives.

${ }^{7}$ I will have little to say about cases where demonstratives are acceptable but their definite counterparts are not, e.g. (8a)-(8b). See King (2001) for a more detailed discussion of such cases.
} 
framework. I argue that demonstratives take an additional, covert argument, and that the function of this covert argument is to pick out a particular individual from the set of individuals that satisfy the demonstrative's overt argument. I posit a non-redundancy condition on this covert argument: the demonstrative's overt argument cannot already denote a singleton in context, i.e. its covert argument cannot be otiose. This explains why, e.g., $(9 \mathrm{~b})$ is unacceptable: the overt predicate 'author of Blood Meridian' already denotes a singleton at the actual world; there is nothing left for the covert argument to do.

Hawthorne \& Manley (2012) and Nowak (2018) also posit a non-redundancy condition on demonstratives (though they do not not formulate the condition in the terms above). What is distinctive about my approach is the way in which I implement this condition. More specifically, I put forward a pragmatic account that ultimately derives the condition through an economy principle discussed by Schlenker (2005). By contrast, Hawthorne \& Manley (2012) and Nowak (2018) try to capture non-redundancy semantically through a presupposition. I argue that my account improves on these presuppositional approaches. ${ }^{8}$

Let me be clear about the target of our discussion. Our focus will be on demonstratives that feature an overt noun phrase, so-called 'complex demonstratives' or 'descriptive demonstratives', rather than demonstratives that do not, so-called 'bare demonstratives' or 'demonstrative pronouns'. This is not because the latter are less interesting than the former. Like complex demonstratives, bare demonstratives can be used in various ways. For instance, consider (13) and (14) below:

(13) [Pointing to a clock on the wall] That has started to run slow.

(14) Every man who owns a donkey beats that and nothing else (Elbourne,

\footnotetext{
${ }^{8}$ In what follows I assume that presupposition is a semantic phenomenon that can be captured in a trivalent system. However, this is mainly for simplicity - all of my arguments are compatible with a pragmatic approach to presuppositions, e.g. (Schlenker, 2008, 2009).
} 
$2008,446)$.

However, bare demonstratives raise difficulties that I do not have the space to consider here. For instance, using a bare demonstrative to pick out a human subject is often infelicitous. For example, it is unacceptable to point at Noam Chomsky and utter (15)-(16):

(15) ?? That wrote Syntactic Structures.

(16) ?? That is an emeritus professor at MIT.

However, I can point at Noam Chomsky and utter (17)-(18):

(17) That is the father of modern linguistics.

(18) That is Noam Chomsky.

Any adequate theory of demonstratives should explain these contrasts. ${ }^{9}$ Since complex demonstratives provide quite enough to keep us occupied, a full treatment of bare demonstratives will have to wait for another day. ${ }^{10}$

The paper is structured as follows. In $§ 2$ I make explicit some of my background semantic assumptions. Then in $\S 3$ I present the non-redundancy condition on demonstratives and explain how it allows us to capture the target contrasts. In $\S \S 4-5$ I consider two implementations of the non-redundancy condition: the semantic, presuppositional approaches of Hawthorne \& Manley (2012) and Nowak (2018); and my preferred pragmatic account. $\S 6$ considers what is arguably the most sophisticated theory of demonstratives in the literature,

\footnotetext{
${ }^{9}$ Similar contrasts are discussed by Yalcin (2014), who attributes them to Mikkelsen (2004).

${ }^{10}$ I will also put to one side so-called "emotive" uses of demonstratives, which are often compatible with semantically unique descriptive content, e.g. (19):

(19) That mother of John Smith is quite a woman! [Wolter (2006) inspired by Lakoff (1974)]

Such uses of demonstratives raise puzzles that I cannot address here. See (Wolter, 2006) for further discussion.
} 
namely the account of Elbourne (2008). I show that Elbourne's semantics on its own is not able to capture the target contrasts, and needs to be supplemented with a pragmatic story like the one I develop earlier in the paper. $\S 7$ concludes. ${ }^{11}$

\section{Preliminaries}

Before I try to explain the target contrasts, I want to make explicit some features of the framework in which our discussion will be set. More specifically, the mechanism by which implicit content is associated with determiner phrases (DPs) in context (§2.1), as well as my chosen background semantics for definite descriptions $(\S 2.2)$.

\footnotetext{
${ }^{11}$ I do not consider the descriptivist proposals of King (2001), Roberts (2002) or Wolter (2006) in detail in this paper. Elbourne (2008) provides a detailed, critical discussion of both King (2001) and Roberts (2002), so perhaps saying more about them is unnecessary here. But I will add a few brief remarks. Since King ties the denotation of a demonstrative to the speaker's intentions, it is clear that his theory, as it stands, cannot account for the relevant contrasts (this point is also observed by Nowak (2014, 428, fn.25)). For instance, supposing that the speaker has the intention to talk about whoever wrote Blood Meridian, King's theory cannot explain why $(9 \mathrm{~b})$ is unacceptable. However, like Elbourne's theory, it is not implausible that King's theory could be supplemented with the sort of pragmatic account that I develop in $\S 5$. As for the accounts of Roberts and Wolter, neither appear to have the empirical reach of Elbourne's account. More specifically, it is unclear how Roberts could account for cases such as (4). When a demonstrative is not being used deictically (as in (1)) Roberts requires that it has an accompanying linguistic antecedent in discourse (so-called "discourse deictic" demonstratives) (Roberts, 2002, 122-123). But the demonstrative in (4) has no accompanying linguistic antecedent. So, in order to handle all of the relevant data, Roberts's conditions need to be relaxed. One might try to amend her account by allowing that no accompanying linguistic antecedent is needed when the relevant entity is "weakly familiar": when the existence of the entity referred to is evident to the participants in the discourse, for example by direct perception or deduction from things that have been said, even though it has not been mentioned (Roberts, 2002, 24). It is arguable that this amendment would handle a sentence such as (4). However, the observation in fn.24 below implies that even if my car is weakly familiar in context, $(34 \mathrm{~b})$ is infelicitous. As for Wolter, it is unclear how she could account for (3). Wolter works within a framework which assigns predicates situation variables that determine where the predicate is to be evaluated. She requires that the situation variable assigned to the argument of the demonstrative determiner be free in the relevant sentence (Wolter, 2006, 64). But quantified cases such as (3) involve binding the situation variable associated with the argument of the determiner. It is unclear how to revise Wolter's account to solve this problem (also see $\S 6$ for a more general problem with this sort of binding).
} 


\section{$2.1 \quad$ Implicit content}

Consider the following:

(20) [We are in a room with only one table]

The table is covered with books.

(21) [We have just finished grading a history exam]

Every student passed.

Intuitively, each DP is restricted by more than just the relevant overt predicate material: the full meaning of (20) is closer to 'The table in this room is covered with books', while the full meaning of (21) is closer to 'Every student in this history class passed'. That is, there is implicit content associated with certain DPs when they are used in context.

I will assume that implicit content is captured by unpronounced elements in the syntactic structures of sentences, i.e. I assume that implicit content is captured by covert material at the level of logical form. Moreover, I will assume that these unpronounced elements modify, or are associated with, nouns rather than determiners. ${ }^{12}$

There are several ways of developing an account of implicit content that satisfies these assumptions, e.g. (Percus, 2000), (Stanley \& Szabó, 2000), (Stanley, 2002), and (Elbourne, 2013). For our purposes it will not matter which particular theory is adopted. However, it will be helpful to have something concrete to work with. So, since it is fairly straightforward, I will assume that implicit content is captured by covert variables that appear on nouns. What this means is that these variables are unpronounced and so have no phonological manifestation; but nevertheless they appear at logical form and so are semantically

\footnotetext{
${ }^{12}$ See (Stanley, 2002) and (Elbourne, 2013) for some arguments in defense of these assumptions.
} 
relevant. Semantically, it is assumed that the denotation of this silent variable is intersected with the semantic value of its sister noun. For instance, (20) can be represented as follows:

(22) The $\langle$ table $\mathcal{V}\rangle$ is covered with books

The angled brackets around 'table $\mathcal{V}$ ' indicates that the variable $\mathcal{V}$ is associated with the noun 'table' (Stanley \& Szabó, 2000, 251). $\mathcal{V}$ is assigned the set of individuals in the relevant room by the contextually determined assignment function. The semantic value of 'table', i.e. the set of tables, is then intersected with the semantic value of $\mathcal{V}$. The sentence ends up meaning 'The table in this room is covered with books' in context, as required. ${ }^{13}$

\subsection{Definite descriptions}

It will be helpful to have an account of definite descriptions on the table. There are various analyses of descriptions in the literature, and it doesn't really matter which we choose. ${ }^{14}$ Since it is fairly straightforward, I will give 'the' a Fregean analysis. ${ }^{15}$ This means that the definite article takes one argument of nounphrase type:

\section{(23) $[\text { the } \mathcal{N}]^{16}$}

\footnotetext{
${ }^{13}$ What has been presented here is a (harmless) simplification in two respects. First, I assume that the semantic value of the covert variable is a set. But this means that, relative to a context, the covert variable will rigidly designate its value, which is problematic (Stanley \& Szabó, 2000, 252). For this reason, the semantic value of the variable is better treated as an intensional entity such as a property, rather than a set. Second, in order to handle quantified cases, the covert structure will likely need to be more complex than simply a set/property variable. See (Stanley \& Szabó, 2000) and (Hawthorne \& Manley, 2012, ch.4.5) for further discussion.

${ }^{14} \mathrm{As}$ far as I can tell, my account of the target contrasts doesn't hang on which particular semantics for descriptions we adopt. For instance, we could have chosen a broadly Russellian, quantificational account. See (Coppock \& Beaver, 2015) for a survey of the various semantics available here.

${ }^{15}$ The lexical entry to follow is similar to the one presented in (Heim \& Kratzer, 1998). Also see (Elbourne, 2013) for a thorough discussion of the Fregean analysis of definite descriptions.

${ }^{16} \mathcal{N}$ is not itself a noun-phrase, since it is a complex made up of a noun-phrase and the variable $\mathcal{V}$. However, given our assumptions above regarding this variable, $\mathcal{N}$ will have the type of a noun-phrase.
} 
Semantically, 'the' is given the following lexical entry:

$\llbracket t h e \rrbracket=\lambda f \in D_{<e, t>}:$ there is exactly one $x$ such that $f(x)=$

1. the unique $y$ such that $f(y)=1^{17}$

On this account, 【the $F \rrbracket$ is defined just in case there is exactly one thing to which $F$ applies; and if there is exactly one thing to which $F$ applies, it denotes this very individual. Otherwise, the description will have no semantic value. Definite descriptions effectively trigger a presupposition that there is exactly one thing to which $F$ applies. For instance, (22) carries a presupposition that there is a unique table in the relevant room, and it is true just in case that object is covered with books.

Since it will be important later on, let me say a bit more about how I am thinking about presuppositions. As is common, I assume that sentences are evaluated against a conversational background that represents the information that interlocutors take for granted in a conversation. Moreover, I assume that this information can be modeled by a set of possible worlds: the context set. The context set is the set of worlds that as far as the interlocutors are concerned are candidates for the actual world.

A natural way of handling presuppositions in this framework is through a satisfaction theory (Stalnaker, 1978). The idea is that sentences that carry presuppositions put constraints on the context set: if a sentence $S$ carries a presupposition $p$ then $S$ can be used to say something true (or false) only if every world in the context set is a $p$-world, i.e. every world in the context set is one in which $p$ is true. Thus, a sentence that carries a presupposition is felicitous only if every world in the context set satisfies that presupposition. So,

\footnotetext{
${ }^{17}$ The lambda binder ' $\lambda$ ' is a device for forming functions. More specifically, a lambda-term $\ulcorner\lambda \alpha: \phi . \delta\urcorner$ is to be understood as "the smallest function which maps every $\alpha$ satisfying $\phi$ to $\delta " . \phi$ is the domain condition, and is introduced by a colon; while $\delta$ is the value description, and is introduced by a period. See (Heim \& Kratzer, 1998, ch.2.5) for further discussion.
} 
(22) will be felicitous only if every world in the context set is one in which there is a unique table in the relevant room.

\section{Non-redundancy}

In this section, I introduce a non-redundancy condition on demonstratives and show how it accounts for the target contrasts. In the following two sections, I present two ways of implementing this condition and argue that the second approach is superior $(\S \S 4-5)$.

Recall that we are trying to explain contrasts such as the following:

(9a) The author of Blood Meridian also wrote The Road.

(9 b) ??That author of Blood Meridian also wrote The Road.

As already mentioned in $\S 1$, what is striking about cases such as this is that the nominal associated with the demonstrative is known to denote a singleton. Although definite descriptions can be used felicitously here, demonstratives cannot. A demonstrative $\ulcorner$ that $F\urcorner$ seems to require that $F$ is not known to denote a singleton: its "job" seems to be to whittle down this non-singleton set to a single member.

A natural way of making sense of this "whittling down" idea is to maintain that demonstratives, unlike descriptions, take two arguments of noun-phrase type:

(25) $[[$ that $X] \mathcal{N}]$

The first argument, $X$, is covert. What this means is that this argument is unpronounced and has no phonological manifestation. Nevertheless, this argument 
is present at logical form, and is therefore semantically relevant. ${ }^{18}$ The second argument, $\mathcal{N}$, is tied to overt material in the sense that the noun it contains is overt. For this reason I will call $\mathcal{N}$ the demonstrative's overt argument. However, the noun inside $\mathcal{N}$ is sister to the covert variable that provides implicit content. So, just to be clear, I am proposing that demonstratives involve (at least) two sorts of covert structure: a covert argument $X$, as well as a covert variable $\mathcal{V}$ that appears in the overt argument. Semantically, I propose that demonstratives trigger (at least) a presupposition that exactly one object satisfies both the demonstrative determiner's overt and covert arguments. If defined, I will assume that a complex demonstrative denotes this very individual.

To handle the target contrasts, the general thought is that felicitous use of a demonstrative involves a non-redundancy condition: the covert argument needs to be non-redundant with respect to the overt argument in the sense that the overt argument cannot already denote a singleton at every world in the context set. In short, the covert argument cannot be idle.

In the next two subsections I will consider two ways of implementing the non-redundancy condition. But notice that however it is spelled out it allows us to capture the target contrasts. For instance, the demonstrative in (9b) can be represented as follows, where $X$ is a placeholder for the relevant covert argument:

(26) $[[$ that $X]\langle$ author of Blood Meridian $\mathcal{V}\rangle]$

No matter what the value of $\mathcal{V}$ is in context, '〈author of Blood Meridian $\mathcal{V}\rangle$ ' will denote either a singleton or the empty set at each world in the context set, since it is common knowledge that only one person wrote Blood Meridian at the actual world. If it denotes a singleton at each world in the context set,

\footnotetext{
${ }^{18}$ ' $X$ ' is intended to be a placeholder for a syntactic structure, e.g. a noun-phrase. I have presented things this way because I want to remain neutral on how exactly this argument is represented at logical form.
} 
then the non-redundancy condition isn't satisfied and $(9 \mathrm{~b})$ is predicted to be infelicitous. Otherwise, for some world $w$ in the context set, '〈author of Blood Meridian $\mathcal{V}\rangle^{\prime}$ denotes the empty set at $w$. Thus, it is not the case that exactly one object satisfies both $X$ and '〈author of Blood Meridian $\mathcal{V}\rangle$ ' at $w$. So, the presupposition triggered by the demonstrative will not be satisfied, in which case $(9 \mathrm{~b})$ is again predicted to be infelicitous. In any event, $(9 \mathrm{~b})$ should be unacceptable.

As for (10 a)-(10 b), the demonstrative in (10 b) ('That only student is Mike') can be represented like this:

\section{$[[$ that $X]$ [only $\langle$ student $\mathcal{V}\rangle]]$}

I will follow Coppock \& Beaver $(2012,535)$ and assume that adjectival 'only' has roughly the following meaning:

$$
\llbracket o n l y \rrbracket=\lambda f \in D_{<e, t>} . \lambda x \in D_{e} . f(x)=1 \wedge \forall y[y \neq x \supset f(y) \neq 1]^{19}
$$

That is, $\ulcorner$ only $F\urcorner$ holds of an individual $x$ just in case $x$ is an individual to which $F$ applies, and no other individual is a thing to which $F$ applies. Suppose that ' student $\mathcal{V}\rangle$ ' denotes a singleton at every world in the context set. Then 'only $\langle$ student $\mathcal{V}\rangle$ ' denotes a singleton at every world in the context set and the non-redundancy condition is not satisfied. Thus, $(10 \mathrm{~b})$ is predicted to be unacceptable. Otherwise, for some world $w$ in the context set, ' $\langle$ student $\mathcal{V}\rangle$ ' does not denote a singleton at $w$, so 'only $\langle$ student $\mathcal{V}\rangle$ ' denotes the empty set at $w$. In this case, the presupposition triggered by the demonstrative will not be satisfied, and (10 b) is also predicted to be unacceptable. This explains why $\ulcorner$ that only $F\urcorner$ is always unacceptable. ${ }^{20}$

\footnotetext{
${ }^{19}$ The condition $f(x)=1$ is usually treated as a definedness condition rather than a "mere entailment", but this won't make a difference for our purposes.

${ }^{20} \mathrm{~A}$ similar explanation can be be given for the unacceptability of demonstratives involving superlatives, such as ( $11 \mathrm{~b})$ ('That fastest horse won the race') from $\S 1$. This result is obtained
} 
Finally, if the demonstrative's overt argument in (12b) ('That winner will receive a lot of money') means something like 'winner of the relevant fight' in context, then the non-redundancy condition will not be satisfied given that it is common knowledge that there was only one winner. Thus, $(12 \mathrm{~b})$ is predicted to be unacceptable. Notice that unlike (9b) and (10b), (12b) is acceptable in other settings. Consider, for instance, a scenario where we are watching a draw for a large cash prize, all of whose contestants are past bingo winners. Once the outcome of the draw has been made manifest, (12 b) can be uttered felicitously. Here it means something like 'That past bingo winner will receive a lot of money'.

In summary, the non-redundancy condition does a good job of explaining the relevant contrasts. Now we will consider some ways of implementing the condition. First, I consider a semantic approach that sees the condition as a presupposition (Hawthorne \& Manley, 2012; Nowak, 2018); and then I consider a pragmatic approach that ultimately derives the condition through an economy principle discussed by Schlenker (2005). I argue that there is good reason to favor the latter account.

\section{First approach: non-redundancy as presuppo- sition}

\subsection{Nowak (2018)}

A natural thought is that the non-redundancy condition should be captured as a constraint on definedness and thus as part of the presupposition introduced by

if, e.g., $\ulcorner$ fastest $F\urcorner$ holds of an individual $x$ just in case $x$ is the fastest thing to which $F$ applies (so that $\ulcorner$ fastest $F\urcorner$ denotes, at most, a singleton). The result is also obtained if a more sophisticated entry for superlatives is used, e.g. that given by Herdan \& Sharvit (2006) (see fn.38 for further discussion). 
the demonstrative. ${ }^{21}$ This is essentially the approach favored by Nowak (2018).

On his account the entry for 'that' can be presented as follows: ${ }^{22}$

$\llbracket t h a t \rrbracket=$

$\lambda f \in D_{<e, t>} . \lambda g \in D_{<e, t>}$ : there is exactly one $x$ such that $f(x)=$

$g(x)=1 \wedge$ there is not exactly one $x$ such that $g(x)=$

1. the unique $y$ such that $f(y)=g(y)=1$

The first argument to the determiner is covert, while the second is tied to overt material. On this account, a demonstrative is defined just in case a unique object satisfies both its overt and covert argument, and its overt argument does not denote a singleton without help from its covert argument. If defined, the complex demonstrative denotes this object. Thus, a demonstrative $\ulcorner$ that $F\urcorner$ triggers a presupposition that $F$ does not denote a singleton. So, $\ulcorner$ that $F\urcorner$ can be used felicitously relative to a context set $C$ only if every world $w$ in $C$ is such that $F$ does not denote a singleton at $w$.

Although this account can capture the relevant contrasts from $\S 1$, making the non-redundancy condition presuppositional is problematic. This can be brought out by considering the coherence of the following:

(30) (a) I don't know if there are any other cars in this showroom, but [pointing to a particular car] that car looks expensive.

\footnotetext{
${ }^{21}$ Although intuitions about these matters are rather delicate, I take the initial motivation for maintaining that non-redundancy is a constraint on definedness rather than a "mere entailment" to be the feeling that nothing is "said" when this condition is not satisfied (but see the arguments immediately below).

${ }^{22}$ On Nowak's account, the covert argument is the second argument to the determiner, rather than the first. Although this difference is significant when it comes to demonstratives that feature postnominal modifiers (see $\S 5.3$ ), it isn't relevant when we restrict our focus to the target contrasts. Moreover, presenting things as in (29) will be more convenient when it comes to discussing my preferred account in $\S 5.2$.

It is worth mentioning that Nowak does not provide an account of implicit content; nor does he explicitly discuss what role implicit content plays with respect to the non-redundancy condition. However, some of his remarks suggest that it is contextually enriched overt predicate material that forms the second argument of the determiner. This is as what we are assuming here. Whether Nowak would endorse all of our assumptions outlined in $\S 2.1$ is unclear, but they do appear to be compatible with his general framework.
} 
(b) I don't know if there's only one person dressed as a witch at this Halloween party, but [pointing to someone dressed as a witch] that witch is very tall.

(c) I don't know if there's only one sandwich in this food truck, but [pointing to a sandwich] that sandwich looks delicious.

(30 a)-(30c) are all acceptable, but this is unexpected if the non-redundancy condition was a presupposition. Usually when a speaker expresses doubt that a certain condition holds and then utters a sentence that has that condition as a presupposition, infelicity results. Consider:

(31) (a) \# I don't know if France is a monarchy, but the King of France is bald.

(b) \# I don't know if Mary ever smoked, but Mary stopped smoking.

(c) \# I don't know if Mark played tennis this morning, but Mark wrote to Mary before he played tennis this morning.

We can explain the infelicity of these sentences as follows. The first conjunct of, e.g. (31 a), signals that the speaker is ignorant about whether France is a monarchy. Since the context models information that is common to interlocutors, this implies that that not every world in the context set is one where France is a monarchy. However, the second conjunct in (31 a) presupposes that France is a monarchy (through the definite 'the King of France'), and thus requires that every world in the context set be one in which France is a monarchy. The result is that (31 a) should be infelicitous, as we observe.

But now consider (30a)-(30 c). In these cases the speaker explicitly signals their ignorance as to whether the overt material for the demonstrative denotes a singleton. Consequently, the context set does not satisfy this condition either. However, in each case the second conjunct is perfectly felicitous. This 
strongly suggests that the non-redundancy condition should not be modeled as a presupposition, and that the entry in (29) is incorrect. ${ }^{23}$

\subsection{Hawthorne \& Manley (2012)}

Before considering my preferred implementation of the non-redundancy condition, I want to briefly discuss another account that is similar to Nowak's. This is the theory of Hawthorne \& Manley.

According to Hawthorne \& Manley (2012, 203-218), specific indefinites ( $\ulcorner$ a/an (specific) $F\urcorner$ ), definite descriptions and demonstratives are all existential quantifiers. However, these expressions differ in terms of the presuppositions they carry. For demonstratives, they also posit something similar to a nonredundancy condition. But they tie this condition to the mechanism that provides implicit content to DPs in context. In terms of our assumptions about implicit content, they maintain that a sentence such as (33 a) can be represented as in $(33 \mathrm{~b})$ :

(33) (a) That table is covered with books.

(b) $[[$ That $\langle$ table $\mathcal{V}\rangle]$ [is covered with books $]]$

On Hawthorne \& Manley's account, (33 b) presupposes that ' $\langle$ table $\mathcal{V}\rangle$ ' denotes a singleton in context, but 'table' does not. More generally, demonstratives

\footnotetext{
${ }^{23}$ Presuppositions that are not satisfied by the context set can sometimes be "accommodated", e.g. even if it is not common knowledge that I have a sister I can say 'I'm visiting my sister this weekend'. However, I take it that it is very difficult, if not impossible, to accommodate a presupposition once the speaker has signaled their ignorance as to whether the presupposition is satisfied.

Interestingly, as Schoubye (2011, 160, fn.6) notes, examples such as (31 a)-(31 c) are improved when the second conjunct is embedded in the antecedent of a conditional:

(32) (a) I don't know if France is a monarchy, but if the King of France is bald, then...

(b) I don't know if Mary ever smoked, but if Mary stopped smoking, then...

Why there should be this contrast is unclear. Schoubye suggests that the contrast marker 'but' license "local accommodation" here so that the antecedent is interpreted at a possible world where the presupposition is satisfied. Whatever the correct explanation of this fact is, accommodation doesn't seem to be available in (31 a)-(31 c).
} 
trigger a presupposition that their first argument (e.g. ' $\langle$ table $\mathcal{V}\rangle$ ') denotes a singleton, but that the relevant overt noun-phrase (e.g. 'table') does not denote a singleton without help from the covert variable $(\mathcal{V}){ }^{24}$

Hawthorne \& Manley's account can explain why (9 b) ('That author of Blood Meridian also wrote The Road') is unacceptable. Since the overt predicate 'author of Blood Meridian' already denotes a singleton, $(9 \mathrm{~b})$ is predicted to be infelicitous. However, Hawthorne \& Manley's account suffers from the problem outlined for Nowak's approach: if non-redundancy is captured in terms of presuppositions, then the felicity conditions of demonstratives will be too strict. Moreover, it seems difficult to implement the account compositionally: 'that' will have to somehow look "inside" its NP argument to know what to yield as a value. Finally, since it relies on the mechanism that provides implicit content to DPs in context, the account cannot explain why demonstratives are unacceptable when the relevant overt predicate only denotes a singleton in combination with covert material. Consider (10 b) ('That only student is Mike'), (11 b) ('That fastest horse won the race'), and (12 b) ('That winner will receive a lot of money') from $\S 1$. Clearly, none of 'only student', 'fastest horse' or 'winner' denotes a singleton without covert supplementation. But this means that Hawthorne \& Manley cannot explain why these sentences are unacceptable in context. ${ }^{25}$

In summary: in terms of the contrasts that we are interested in, Hawthorne \& Manley's account does not improve on Nowak's presuppositional approach that I presented in $\S 4.1 .^{26}$

\footnotetext{
${ }^{24}$ Hawthorne \& Manley also maintain that covert material supplied by the covert variable must be salient. This is supposed to explain the contrast between $(34 \mathrm{a})$ and $(34 \mathrm{~b})$ when both are uttered discourse initially and without any associated demonstrations:

(34) (a) I took the car to the garage last night.

(b) I took ??that car to the garage last night (Hawthorne \& Manley, 2012, 209).

Even if the audience can exploit a background assumption that the speaker has only one car, if no car is salient then there will be no salient covert material to restrict the denotation of the overt noun-phrase 'car'. In this case, $(34 \mathrm{~b})$ is predicted to be infelicitous.

${ }^{25}$ Note that in each case we can make the covert material as salient as we like, e.g. by pointing to the relevant objects - this makes no difference to (un)acceptability.

${ }^{26}$ In fairness to Hawthorne \& Manley, after giving their account they say "no doubt this
} 


\section{Second approach: non-redundancy as econ- omy}

We have just seen that maintaining that the non-redundancy condition has a semantic basis is problematic. Instead, I want to suggest that it has a pragmatic source. The basic idea is that demonstratives are in competition with definite descriptions: a demonstrative may not be used if a definite can be. What drives this competition is an economy principle. I unpack and motivate these thoughts over the course of this section.

\subsection{Minimize Restrictors! ${ }^{27}$}

Schlenker (2005) draws attention to contrasts such as the following:

(35) (a) John's father has arrived

(b) ?? John's blond father has arrived

(36) (a) The American president is in the next room

(b) ?? The educated American president is in the next room [We all know that there was exactly one witch at John's Halloween party]

(a) The witch left early

(b) ?? The tall witch left early

The (b) member of each pair sounds worse than the (a) member. Intuitively, this is because the definite description in these sentences contains redundant sketch is inadequate' (Hawthorne \& Manley, 2012, 209).

${ }^{27}$ Thanks to both Cian Dorr and Philippe Schlenker for independently drawing my attention to (Schlenker, 2005) and the principle of Minimize Restrictors! 
material, e.g. 'tall' in $(37 \mathrm{~b})$ could be dropped without affecting the denotation of the description. These observations motivate Schlenker $(2005,7)$ to introduce the following principle, which he calls Minimize Restrictors!:

(38) Minimize Restrictors! ${ }^{28}$

Relative to a context set $C$, a definite description the $A B$ is deviant if $A$ is redundant, i.e. if:

(i) the $B$ is grammatical and $B$ denotes a singleton at every world in $C$, and

(ii) $A$ does not serve another purpose, i.e. it is pragmatically irrelevant.

Condition (ii) in (38) is there to handle the felicity of sentences such as 'The idiotic American president made another blunder'. The idea is that although 'idiotic' can be dropped without altering the denotation of the description, it serves a "pragmatic" function in the sense that it helps to express the speaker's opinion of the American president. ${ }^{29}$

Schlenker $(2005,4)$ suggests that what drives Minimize Restrictors! are considerations of economy: 'Minimize Restrictors! is presumably a special case of a Gricean principle, probably what Levinson (1998) calls the "Maxim of Minimization", which he states as the following injunction: Produce the minimal linguistic clues sufficient to achieve your communicational ends'. To be complete, it should be shown how precisely Minimize Restrictors! can be derived. But we will not do that here. Instead, I will just assume Minimize Restrictors! and see how it helps us account for the non-redundancy condition on demonstratives. ${ }^{30}$

\footnotetext{
${ }^{28} \mathrm{My}$ formulation of Minimize Restrictors! varies slightly from Schlenker's, but as far as I can tell these differences are not significant.

${ }^{29}$ There is clearly much more to be said about condition (ii). For instance, even if 'stupid' has an expressive function, 'The stupid only student is angry' is still unacceptable. See (Blumberg, 2018) for further discussion of this issue. Also see (Marty, 2017) for a more general discussion of condition (ii).

${ }^{30}$ One might think that Minimize Restrictors! could be derived from the sort of general redundancy principles that have been discussed by Fox (2007); Singh (2011); Mayr \& Romoli
} 


\section{$5.2\ulcorner$ that $F\urcorner$ and $\ulcorner$ the $X F\urcorner$}

This is the simple semantics for demonstratives that I propose:

$$
\begin{aligned}
& \llbracket \text { that } \rrbracket= \\
& \lambda f \in D_{<e, t>} \cdot \lambda g \in D_{<e, t>}: \text { there is exactly one } x \text { such that } f(x)= \\
& g(x)=1 \text {. the unique } y \text { such that } f(y)=g(y)=1
\end{aligned}
$$

Once again, the first argument to the determiner is covert, while the second is tied to overt material. On this account, a demonstrative is defined just in case a unique object satisfies both its overt and covert argument. If defined, the complex demonstrative denotes this object.

What the above entry does, essentially, is make a demonstrative $\ulcorner$ that $F\urcorner$ equivalent to a definite description $\ulcorner$ the $X F\urcorner$, where $X$ is the covert argument

(2016); and Blumberg (2017). For instance, these authors appeal to principles such as the following: $\phi$ cannot be used in context $C$ if $\phi$ and $\psi$ have the same assertive content relative to $C$, and $\psi$ is a simplification of $\phi$ ( $\psi$ is a simplification of $\phi$ if $\psi$ can be derived from $\phi$ by replacing nodes in $\phi$ with their subconstituents). Assertive strength is commonly defined as follows: clauses $F$ and $F^{\prime}$ have the same assertive content relative to $C$ just in case $\left\{w: F^{\prime}\right.$ is true in $\left.w\right\}=\{w: F$ is true in $w\}$. However, although (36a) is a simplification of (36 b), even if is not commonly known that the American president is educated, $(36 \mathrm{~b})$ is infelicitous. That is, (36a) and (36 b) need not have the same assertive content relative to $C$ in order for $(36 \mathrm{~b})$ to be infelicitous. (See (Blumberg, 2018) for some reasons why, in this case, the infelicity can't be explained by simply maintaining that the presuppositions of (36 b) aren't satisfied.)

For a similar reason, Minimize Restrictors! cannot be derived from the principle of Maximize Presupposition (Heim, 1991; Percus, 2006; Schlenker, 2012): if a sentence $S$ is a presuppositional alternative of a sentence $S^{\prime}$ and the context $C$ is such that (i) the presuppositions of $S$ and $S^{\prime}$ are satisfied in $C$; (ii) $S$ and $S^{\prime}$ have the same assertive content relative to $C$; and (iii) $S$ carries a stronger presupposition than $S$, then $S$ should be preferred to $S^{\prime}$ (this formulation is due to Schlenker $(2012,393))$. As Marty (2017) points out, $\ulcorner$ the $B\urcorner$ does not trigger stronger presuppositions than $\ulcorner$ the $A B\urcorner$. Presuppositional strength is commonly defined as follows: a clause $F$ carries a stronger presupposition than a clause $F$ ' just in case $\left\{w: F^{\prime}\right.$ is undefined in $\left.w\right\} \subsetneq\{w: F$ is undefined in $w\}$. But now consider a world $w$ with the following features: $\left|A_{w}\right|=0,\left|B_{w}\right|=1$. At $w$, the presupposition triggered by $\ulcorner$ the $B\urcorner$ will be satisfied, but the presupposition triggered by $\ulcorner$ the $A B\urcorner$ will not be.

Marty (2017, ch.3) tries to derive a principle similar to Minimize Restrictors! from a more general theory of implicatures. However, in order to predict that $(36 \mathrm{~b})$ is infelicitous in context, he requires that ( $36 \mathrm{~b}$ ) and (36 a) be contextually equivalent. But as noted above, this isn't necessary for ( $36 \mathrm{~b}$ ) to be unacceptable. (Also see fn. 41 for further discussion of Marty's attempt to derive Minimize Restrictors!.) I suspect that Minimize Restrictors! is partly the product of a principle recently discussed by Anvari (2018) called "Logical Integrity", for this would explain why $\ulcorner$ the $A B$ is $G\urcorner$ is infelicitous even when it isn't contextually equivalent to $\ulcorner$ the $B$ is $G\urcorner$. However, this still leaves condition (ii) of Minimize Restrictors! unaccounted for. See (Blumberg, 2018) for further discussion of this topic. 
to the demonstrative. Given Minimize Restrictors! discussed above, this is all we need to explain the relevant contrasts. Let me expand on this. Minimize Restrictors! tells us that $\ulcorner$ the $X F\urcorner$ enters into competition with $\ulcorner$ the $F\urcorner$. I claim that because $\ulcorner$ that $F\urcorner$ and $\ulcorner$ the $X F\urcorner$ are semantically equivalent, $\ulcorner$ that $F\urcorner$ also enters into competition with $\ulcorner$ the $F\urcorner$. This gives us the following Competition Principle:

(40) Competition Principle

Relative to a context set $C$, a demonstrative that $F$ is deviant if (where $X$ is the covert argument to the demonstrative):

(i) the $F$ is grammatical and $F$ denotes a singleton at every world in $C$ and

(ii) $X$ does not serve another purpose, i.e. it is pragmatically irrelevant.

Ignoring condition (ii), which we will return to shortly, it is clear that the Competition Principle implies the non-redundancy condition on demonstratives: if $F$ denotes a singleton at every world in the context set, then $\ulcorner$ the $F\urcorner$ is preferred, rendering $\ulcorner$ that $F\urcorner$ infelicitous. This explains the contrasts from above (repeated below):

(9a) The author of Blood Meridian also wrote The Road.

(9 b) ??That author of Blood Meridian also wrote The Road.

(10 a) The only student is Mike.

(10 b) ?? That only student is Mike.

(12 a) The winner will receive a lot of money.

(12 b) ?? That winner will receive a lot of money. 
To reiterate, on the account I am proposing the (b) member in each pair is infelicitous because demonstratives and definites are in competition, and definites are preferred to demonstratives. They are preferred, ultimately, for reasons of economy: demonstratives take a covert argument making $\ulcorner$ that $F\urcorner$ equivalent to $\ulcorner$ the $X F\urcorner$, where $X$ is covert. $\ulcorner$ the $F\urcorner$ is more economical than $\ulcorner$ the $X F\urcorner$ when they have the same denotation. And they will have the same denotation exactly when $F$ denotes a singleton, as all of 'author of Blood Meridian', 'only student', and 'winner' do in context.

Not only does this pragmatic approach explain the relevant contrasts, but it also makes sense of data that was problematic for the account based on presuppositions sketched above. The problem involved cases such as the following:

(30 b) I don't know if there's only one person dressed as a witch at this Halloween party, but [pointing to someone dressed as a witch] that witch is very tall.

On the presuppositional approach, felicitous use of a demonstrative $\ulcorner$ that $F\urcorner$ requires that every world in the context set be one in which $F$ does not denote a singleton. It follows that the speaker needs to believe that $F$ does not denote a singleton. By contrast, on the pragmatic approach we get something weaker. By choosing to use a demonstrative $\ulcorner$ that $F\urcorner$, we may only infer that it is not commonly believed that $F$ denotes a singleton, for otherwise the speaker would have used the definite $\ulcorner$ the $F\urcorner$. This weaker condition is of course compatible with the first conjunct in $(30 \mathrm{~b})$ : the speaker does not believe that 'witch' denotes a singleton. Thus, the pragmatic implementation of non-redundancy 
improves on the presuppositional approaches discussed in $\S 4.31,32$

Now that I have presented my favored explanation of the relevant contrasts, I want to end this section by considering some possible challenges for my account.

\subsection{Possible worries}

First, let us return to the matter of condition (ii) of the Competition Principle. It might be argued that the approach put forward predicts that $\ulcorner$ that $F\urcorner$ can be felicitous when $F$ denotes a singleton. This should happen whenever condition (ii) of the Competition Principle is contravened, i.e. the demonstrative's covert argument serves a pragmatic purpose. For instance, it seems to predict that (42) should be acceptable when the covert argument for the demonstrative is something like 'idiotic', since (43) is perfectly fine.

(42) ?? That American President is in the next room.

(43) The idiotic American President is in the next room.

But this is a bad prediction, for the demonstrative is not acceptable even if the speaker holds a low opinion of the President.

\footnotetext{
${ }^{31}$ To be sure, use of a demonstrative does often communicate the stronger claim that it is commonly believed that $F$ does not denote a singleton. What this shows is that inferences based on the Competition Principle are often strengthened through an "epistemic step" where

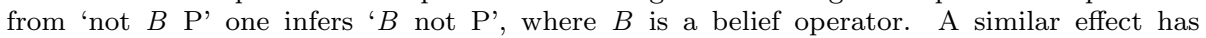
been observed for scalar implicatures (Sauerland, 2004), for so-called "antipresuppositions" (Chemla, 2007), and for general redundancy-based inferences (Blumberg, 2017). I am hopeful that the explanation for the epistemic step for antipresuppositions presented in (Chemla, 2007) can be applied to the Competition Principle, but this matter requires a more detailed investigation.

${ }^{32} \mathrm{As}$ a reviewer observes, the phenomenon of interest carries over to the plural case as well: [Mary has pictures of all Olympic 100m gold medalists and Olympic 200m gold medalists.]

(a) The $100 \mathrm{~m}$ gold medalists look fitter than the $200 \mathrm{~m}$ gold medalists.

(b) ?? Those $100 \mathrm{~m}$ gold medalists look fitter than ?? those $200 \mathrm{~m}$ gold medalists.

As the reviewer notes, my account can explain such contrasts so long as we replace the definite's uniqueness presupposition with a maximality presupposition (Sharvy, 1980).
} 
In response, I claim that condition (ii) of the Competition Principle is hardly ever contravened. The demonstrative's covert argument will serve a pragmatic purpose when it signals the speaker's attitude towards the denotation of the demonstrative. However, it is plausible that the argument being covert, or unpronounced, forms a principled barrier to this sort of signaling. That is, in order for predicative material to serve an expressive function, it generally needs to be overt and manifest to the audience. Thus, it is in the nature of covert material to not be able to fulfill an expressive function. Therefore, it is no surprise that although (43) is acceptable, (42) is rarely felicitous. Note that this response predicts that when the covert material is communicated by other means, e.g. intonation, the demonstrative should improve. This does appear to be what we find: when 'that' is emphasized in (42) and the sentence is uttered in a haughty, supercilious way, it does seem to sound better.

Second, one might worry about cases where both demonstratives and definite descriptions are acceptable. Consider the following context and sentences that follow it:

Lone Car: We live in a neighborhood that forbids cars on its roads-residents are encouraged to walk or ride bicycles. One day we wake up to find a white Toyota parked outside our apartment. A while later you phone me from your office to ask if anything's changed. I reply:

(44) (a) The car is still parked outside our apartment.

(b) That car is still parked outside our apartment.

Both (44a) and (44b) are acceptable, but this is surprising given the Competition Principle: since the definite is acceptable, the demonstrative shouldn't be. $^{33}$

\footnotetext{
${ }^{33}$ Thanks to Ben Holguín for discussing this worry with me and inspiring this example.
} 
Observe that Minimize Restrictors! also appears to be contravened in the context of Lone Car, for (45) is also an acceptable reply:

(45) The white car is still parked outside our apartment.

Given that 'white' doesn't serve a pragmatic function, Minimize Restrictors! seems to predict that (45) should be infelicitous.

A plausible response here is that the value of the silent variable $\mathcal{V}$ appearing on the noun 'car' takes a different value in (44 a) and (44 b)-(45). More specifically, while ' $\langle$ car $\mathcal{V}\rangle$ ' denotes a singleton in $(44 \mathrm{a})$, it does not denote a singleton in (44b)-(45). Since the Competition Principle (and Minimize Restrictors!) is intended to take implicit content into account, there is no problem. Further motivation for this sort of response comes from well known data that suggests quantifier domains can shift rapidly and without speakers' explicit awareness, e.g. 'Everyone is asleep and is being monitored by a research assistant' and 'Every sailor waved to every sailor' (Westerståhl, 1985; Soames, 1986; Stanley \& Szabó, 2000). ${ }^{34}$

As an anonymous reviewer points out, many demonstratives that take a "donkey anaphoric" reading can be substituted for their definite counterparts without a change in acceptability, e.g. (46 a)-(46 b):

(46) (a) Every boy who danced with a girl kissed the girl.

\footnotetext{
${ }^{34}$ Note that the felicity of both $(44 \mathrm{a})$ and $(44 \mathrm{~b})$ poses a problem for Hawthorne \& Manley's account presented in $\S 4.2$, given the principle Maximize Presupposition: among a set of competitors whose logical forms have the same assertive content relative to the context, choose the one that marks the strongest presupposition (see $\mathrm{fn} .30$ for a more detailed presentation of this principle). On Hawthorne \& Manley's account the presuppositions of demonstratives are stronger than the presuppositions of definite descriptions. On this theory, felicitous use of a definite description presupposes that it is "candidly" restricted to a singleton, i.e. that "the audience can grasp how a quantified expression is being restricted without having to access it in a way that is cognitively parasitic on that very use of the expression' (Hawthorne \& Manley, 2012, 140). As Hawthorne \& Manley $(2012,210)$ point out, the non-redundancy condition on demonstratives is just a refined candidness condition: if the audience is in a position to grasp how the demonstrative is being restricted using salient supplemental information, then clearly the audience is able to non-parasitically grasp how the demonstrative is being restricted. Thus, Maximize Presupposition says that (44 b) should be preferred. However, as we have seen, $(44 \mathrm{a})$ is perfectly felicitous.
} 
(b) Every boy who danced with a girl kissed that girl. ${ }^{35}$

The proper semantic analysis of these constructions is a controversial matter, and it is beyond the scope of this paper to give a detailed account of how the relevant readings arise. ${ }^{36}$ However, I am hopeful that the sort of strategy outlined in response to (44a)-(44 b) could be helpful here too. That is, I want to suggest that the acceptability of both $(46 \mathrm{a})$ and $(46 \mathrm{~b})$ can be explained by appealing to shifts in the implicit content associated with 'girl'. Here is a rough sketch of the general idea. When we interpret ( $46 \mathrm{a}$ ) the value of the definite's restrictor is, e.g. $K_{i}$ : the set of girls kissed by $i$, where $i$ is the relevant boy. But when we interpret ( $46 \mathrm{~b}$ ), the value of the demonstrative's overt restrictor is larger, perhaps the set of all girls. Instead, here it is the covert restrictor to the demonstrative, $X$, that takes the value $K_{i}$. Thus, there is no contravention of the Competition Principle, and supposing that each boy danced and kissed exactly one girl, both (46a) and (46 b) should be acceptable. ${ }^{37,38}$

\footnotetext{
${ }^{35}$ These cases are the definite and demonstrative counterparts of sentences such as (47): (47) Every boy who danced with a girl kissed her.

Such constructions pose the following problem: the pronoun clearly isn't referring to any particular girl, and familiar ways of interpreting it as a variable bound by 'a girl' don't give the right truth-conditions. Put another way, the choice of girl seems to co-vary with the choice of boy, but it is unclear how this reading is achieved given standard binding principles. The literature on this topic is enormous: see (King \& Lewis, 2016) for a survey; (Abbott, 2002) contains a discussion of donkey demonstratives in particular.

${ }^{36}$ See, e.g. (Heim, 1990) and (Elbourne, 2005).

${ }^{37}$ In order to make these ideas precise, the covert structure that provides implicit content will need to be more complex than simply a set variable. See fn. 13 .

${ }^{38} \mathrm{~A}$ reviewer suggests that even demonstratives that feature superlatives are acceptable when they take donkey anaphoric readings:

(48) Every race organizer praised the fastest horse (in his race) and the jockey who mounted that fastest horse.

This seems to raise the following problem: if 'fastest horse' invariably denotes a singleton (supposing it denotes anything at all), then appealing to shifts in the value of the variable that provides implicit content can't explain why (48) is unproblematic. However, cases such as (48) can be accounted for if an independently motivated entry for superlatives is adopted, namely that of Herdan \& Sharvit (2006). On this semantics, superlatives have a context sensitive meaning that allows, e.g. 'fastest horse' to denote the set of horses each of which are fastest in their respective race. That is, on this semantics 'fastest horse' needn't denote a singleton. We can then argue that the superlative denotes a singleton when it appears on the definite in (48) (e.g. the singleton containing the unique fastest horse in the relevant race), but does not denote a singleton when it appears on the demonstrative in (48) (e.g. the set of horses each of which is fastest in their respective races). In this case, there is no problem for
} 
Finally, there are cases where it is uncontroversial that the overt argument to the demonstrative denotes a singleton and yet the demonstrative is perfectly felicitous. These are cases that involve postnominal modifiers. Such examples have been discussed by Wolter (2006), Hawthorne \& Manley (2012) and Nowak (2018). Consider the contrast between (49a)-(49 b), and (50a)-(50 b):

(49) (a) ?? That tallest German will win the prize

(b) That man who is tallest among Germans will win the prize (Hawthorne \& Manley, 2012, 209, fn.19).

(c) The man who is tallest among Germans will win the prize.

(50) (a) ?? That author of Blood Meridian is a good writer.

(b) That guy who wrote Blood Meridian is a good writer [adapted from (Nowak, 2015, 3)].

(c) The guy who wrote Blood Meridian is a good writer.

As my account predicts, the (a) members are unacceptable since their overt arguments denote a singleton. However, my account also predicts that the (b) members - both of which have a nominal modified by a relative clause - should be unacceptable, since the (c) members are perfectly felicitous. But this is not what we find. ${ }^{39}$

I think that these contrasts raise a real puzzle. However, I think that this puzzle involves the functioning of postnominal modifiers rather than demonstratives. To see this, note that postnominal modifiers seem to bring a counterexample to Minimize Restrictors!:

(51) (a) ?? The tall author of Blood Meridian is a good writer.

the Competition Principle.

${ }^{39}$ Also see Wolter (2006, ch.4) for many examples of felicitous demonstratives that involve a variety of postnominal modifiers. King's (2001) 'no demonstration no speaker reference' uses also all seem to involve postnominal modification. 
(b) The tall guy who wrote Blood Meridian is a good writer.

(c) The guy who wrote Blood Meridian is a good writer.

As predicted by Minimize Restrictors!, (51 a) is unacceptable. However, (51 b) is felicitous which is surprising given that $(51 \mathrm{c})$ is as well. ${ }^{40}$

It is unclear how best to explain these contrasts, and why postnominal modifiers exhibit this behavior. ${ }^{41}$ But it should be clear that, e.g. (49a)-(49c) do not undermine my account. If anything these contrasts provide further support for the sort of approach that I have developed here: the fact that postnominal modifiers bring similar counterexamples to Minimize Restrictors! suggests that my account is on the right track, and that there is a close relationship between $\ulcorner$ that $F\urcorner$ and $\ulcorner$ the $X F\urcorner \cdot{ }^{42,43}$

\footnotetext{
${ }^{40}$ As Wolter (2006) observes, a similar contrast arises with free choice 'any':
}

(52) (a) ??Any man didn't eat dinner.

(b) Any man who saw the fly in the food didn't eat dinner (Dayal, 1998, 434-435).

An 'any' phrase can become acceptable when modified by a subordinate clause, e.g. a relative clause - a phenomenon known as subtrigging (Dayal, 1998, 434).

${ }^{41}$ It is worth noting that Marty's (2017) theory might be able to explain why postnominal modifiers are able to disrupt the functioning of Minimize Restrictors!. Marty essentially derives Minimize Restrictors! from the presence of a covert exhaustification operator. It is commonly maintained that this operator is sensitive to the syntactic structure of its complement (Katzir, 2007). More specifically, the set of relevant alternatives is determined syntactically. It is plausible that when postnominal modifiers are present, the set of alternatives is affected in such a way that the relevant non-uniqueness effects no longer arise. If this is correct, then our observations above would constitute a striking argument in favor of Marty's account (and accounts that try to derive Minimize Restrictors! through exhaustification more generally). See (Blumberg, 2018) for further discussion.

${ }^{42}$ In response to contrasts such as (49a)-(49 b), Nowak (2018) maintains that in some cases involving postnominal modification the modifier may be attached high in the syntactic tree (adopting the proposal of Bach \& Cooper (1978)), so that the modifier takes the place of what is usually the covert argument and the head noun takes the place of what is usually the overt argument. This handles examples such as (49 b), since the head noun 'man' does not denote a singleton without help from the relative clause 'who is tallest among Germans'.

However, there are problems with this response. For one thing, the sort of movement it posits is not possible on dominant theories of the syntax of postnominal modification (Bhatt, 2002). Moreover, this response still can't handle cases such as the following:

(53) Most avid snow skiers remember that first black diamond run they attempted to ski (King, 2001, 10).

Relative to a snow skier $x$, 'first' needs to take as argument 'black diamond run $x$ attempted to ski' - the head noun can't be separated from the rest of the clause. Finally, adopting a non-standard syntax for postnominal modifiers does not explain the contrast between (51 a) and $(51 \mathrm{~b})$ : attaching the modifier high in the syntactic tree doesn't alter the interpretation of definite descriptions. However, it is plausible that the contrast between (51 a $)-(51 \mathrm{~b})$ and (50 a)-(50 b) should be accounted for in the same way.

${ }^{43}$ Hawthorne \& Manley briefly consider the problem of postnominal modifiers and maintain 


\section{Elbourne (2008)}

In this section, I discuss what is arguably the most sophisticated theory of demonstratives in the literature, namely the account of Elbourne (2008). My preferred semantics is similar to Elbourne's account, and might even be considered a variant of it. However, my major aim here is to show that Elbourne's semantics on its own does not have the resources to explain the contrasts from $\S 1$.

Building on work by Nunberg (1993), Elbourne (2008, 429-430) holds that demonstrative determiners such as 'that' take three arguments: an individual variable $i$, a relation variable $R$, and a noun-phrase. The first two arguments are covert, while the third is overt. This yields the following configuration:

$$
\left[\left[\left[\text { that } i_{1}\right] R_{2}\right] \mathrm{NP}\right]
$$

The value of $\mathrm{i}$ is an individual that Elbourne calls the index, while the value of $\mathrm{R}$ is a relation from individuals to things of the type of noun-phrases. Semantically, 'that' is given the following lexical entry:

$$
\llbracket t h a t \rrbracket=\lambda z \in D_{e} . \lambda f \in D_{<e, e t>} \cdot \lambda g \in D_{<e, t>}:
$$

there is exactly one $x$ such that $f(z)(x)=g(x)=1 \wedge$

$z$ is distal from the speaker. the unique $y$ such that $f(z)(y)=g(y)=1^{44}$

that these modifiers should count as supplemental and automatically salient, and that what matters is whether the head noun denotes a singleton. That is, the proposal is that felicitous use of a demonstrative presupposes that the head noun does not denote a singleton without help from additional material (either covert material or a postnominal modifier), and that this additional material is salient. But notice that this response leads to further problems with the principle of Maximize Presupposition. If relative clauses are supplemental and automatically salient, then Maximize Presupposition predicts that sentences such as (49c) should be unacceptable, since $(49 \mathrm{~b})$ involves stronger presuppositions because it contains a demonstrative. Thus, Maximize Presupposition says that (49b) should be preferred. However, (49c) is perfectly felicitous.

${ }^{44}$ What is given is a simplification of Elbourne's entry, since he works in a situation semantics where each type is 'raised' by an intensional parameter, e.g. the type of a noun-phrase is $\langle s e, s t\rangle$ rather than $\langle e, t\rangle$. See (Elbourne, 2008, 429-430) for the details, and see below for a potential problem with trying to reconcile Elbourne's situation semantics with the pragmatic mechanism presented in $\S 5$. 
In words, what (55) says is that 'that' takes an individual $z$ (the index), a relation $f$ (the value of $\mathrm{R}$ ), and a function $g$ (the value of the the overt nounphrase), and returns a unique individual $x$ that satisfies the following conditions: $f(z)(x)=1$ (i.e. $z$ bears the relation $f$ to $x$ ), $g(x)=1$ (i.e. $x$ has the property $g$ ), and $z$ is distant from the speaker (at the relevant point of evaluation). ${ }^{45}$

To see how this account is supposed to work, let us run through a few cases. Perhaps it is best to begin with a case of deferred ostension such as (2) from above:

(2) [Pointing to a copy of On Denoting] That man was a genius.

According to Elbourne, a simplified LF for (2) is given by (57):

$$
\text { [[[that } \left.\left.i_{1}\right] R_{2}\right] \text { man] was a genius] }
$$

Here, the index is the particular copy of On Denoting that I am pointing to, while the value of $\mathrm{R}$ relates books to their authors:

(58) (a) $\llbracket \mathrm{i}_{1} \rrbracket^{g}=$ a copy of On Denoting

(b) $\llbracket \mathrm{R}_{2} \rrbracket^{g}=\lambda x \in D_{e} . \lambda y \in D_{e} . y$ authored $x$

(c) $\llbracket \mathrm{R}_{2} \mathrm{i}_{1} \rrbracket^{g}=\lambda y \in D_{e} . y$ authored On Denoting

Thus, on Elbourne's account (2) is defined just in case there is exactly one individual who authored On Denoting and is a man, and the particular copy of On Denoting is distant from the speaker. If defined, (2) is true just in case Bertrand Russell, i.e. the man who authored On Denoting, is a genius.

\footnotetext{
${ }^{45}$ Notice that on this account it is the index, and not the denotation of the demonstrative that determines the distal feature. This is in order to account for cases such as the following (Nunberg, 1993, 23). Suppose I point to two sample plates in my china shop. The first one is right in front of me, but the second is across the room. I say:

(56) These [I gesture at the nearby plate] are over at the warehouse, but those [I gesture at the distant plate] I have in stock here.

If the denotations and not the indices of 'these' and 'those' were what was relevant here, then I should have used the one where I used the other.
} 
Now consider a deictic use of a demonstrative, such as (1):

(1) [Pointing at Pete] That man plays tennis.

The index in this case is Pete, while the value of $\mathrm{R}$ is the identity relation:

(59) (a) $\llbracket \mathrm{i}_{1} \rrbracket^{g}=$ Pete

(b) $\llbracket \mathrm{R}_{2} \rrbracket^{g}=\lambda x \in D_{e} \cdot \lambda y \in D_{e} \cdot y=x$

(c) $\llbracket \mathrm{R}_{2} \mathrm{i}_{1} \rrbracket^{g}=\lambda y \in D_{e} \cdot y=$ Pete

Thus, on Elbourne's account (1) is defined just in case there is exactly one individual who is a man and is identical to Pete, and Pete is distant from the speaker. If defined, (1) is true just in case Pete plays tennis. ${ }^{46}$

It should be clear that the semantics presented in $\S 5.2$ is very similar to Elbourne's theory. The major difference is that Elbourne's account is more complex: it posits an additional covert argument and also makes use of a distal feature. Now, it might be thought that this increased complexity allows us to account for the relevant contrasts. More specifically, it might be thought that our contrasts can be explained by putting constraints on what can and can't play the role of indices and relations. To motivate this, consider once again one of our target contrasts:

(9a) The author of Blood Meridian also wrote The Road.

(9 b) ??That author of Blood Meridian also wrote The Road.

As we have seen, on Elbourne's account a demonstrative has a semantic value only if there exists an index for the individual variable. It could be argued that when, e.g. (9b) is uttered out of the blue there are simply no suitable

\footnotetext{
${ }^{46}$ Elbourne $(2008,434-435)$ uses a system that involves assigning situation pronouns to predicates, and captures the rigidity of deictically used demonstratives by appealing to an operator that shifts the assigned situation pronoun to the actual world.
} 
individuals that could play the role of indices. So, it might be maintained that Elbourne's account explains why $(9 \mathrm{~b})$ should be infelicitous.

However, even when I utter (9b) while pointing at Cormac McCarthy it is still infelicitous. Assuming that the index is the man Cormac McCarthy in this case, and the relevant relation is just the identity relation, $(9 \mathrm{~b})$ will be virtually semantically identical to $(9 \mathrm{a})$. Since the latter is acceptable, it is difficult to see why the former should be infelicitous. More generally, given Elbourne's treatment of deictically used demonstratives, it is unclear why any of (9b)(12 b) should be infelicitous when their demonstratives are used deictically.

To sum up, I don't think that our target contrasts can be explained by maintaining that appropriate arguments for the demonstrative determiner are unavailable. Thus, Elbourne's account as it stands cannot help to explain these contrasts. However, so long as Elbourne's theory is construed broadly enough, i.e as in (55), there is no bar to him supplementing it with the pragmatic mechanism that I presented in $\S 5$.

Although I think that Elbourne would do well to adopt my pragmatic account presented above, I want to end this section by bringing out a tension between some features of Elbourne's preferred semantic framework and the Competition Principle. ${ }^{47}$ To see this, recall our observation in $\S 5.3$ that in some cases it appeared that $\ulcorner$ the $F\urcorner$ and $\ulcorner$ that $F\urcorner$ are both acceptable, in contravention of the Competition Principle. Our response to this worry was to maintain that the implicit content associated with the DP was different in each example, so that the meaning of the covertly supplemented overt noun-phrase differed across cases.

The problem for Elbourne involves examples such as the following:

(60) (a) Mary talked to no senator before that senator was lobbied

\footnotetext{
${ }^{47}$ Thanks to Cian Dorr for discussion here.
} 
(Elbourne, 2008, 445-446).

(b) Mary talked to no senator before the senator was lobbied.

Both of these sentences are acceptable. However, Elbourne's chosen semantic framework is a situation semantics where quantifiers are essentially able to bind the variables that provide implicit content to DPs. For instance, putting technical details to one side, in $(60 \mathrm{a})-(60 \mathrm{~b})$ the "covariation" of senators that were lobbied with those that Mary talked to is captured by allowing the quantifier 'no senator' to bind the variable that provides implicit content to 'that senator'/'the senator' (Elbourne, 2008, 445-446). This means that the implicit content associated with the demonstrative in, e.g., (60a) and the definite in (60 b) cannot be distinguished. Thus, Elbourne cannot explain why both (60 a) and $(60 \mathrm{~b})$ are acceptable by appealing to differences in implicit content, i.e. he cannot make use of the strategy that we employed in $§ 5.3$. But if Elbourne adopts the Competition Principle, then some such explanation must be given, for the demonstrative and the definite will be in competition here. ${ }^{48}$

Of course, it is not compulsory to have quantifiers behave as they do in Elbourne's framework. However, this approach to quantification is arguably the centrepiece of Elbourne's account of "donkey" phenomena that involve socalled cases of "covariation without c-command". So, giving it up would require a rather large departure from his chosen system. I leave how to reconcile the Competition Principle with Elbourne's preferred semantic framework as an open issue.

\footnotetext{
${ }^{48} \mathrm{~A}$ similar problem arises with cases of donkey anaphoric demonstratives, e.g. (46 b) ('Every boy who danced with a girl kissed that girl').
} 


\section{Conclusion}

There are considerable challenges for those who wish to provide a unified account of complex demonstratives: an adequate theory needs to allow demonstratives to behave like definite descriptions in some cases, but also pattern differently from definite descriptions in others. In this paper, I focused on the latter challenge. I put forward a pragmatic account of the target contrasts that builds on an economy principle discussed by Schlenker (2005). I also argued that my preferred approach does better than the most sophisticated existing theories with respect to these contrasts.

I believe that the approach to demonstratives presented in this paper is on the right track. However, there is still much work to be done on this topic. Hopefully the data that we have discussed here will be helpful for future research, and the positive proposal presented above will provide a basis for further inquiry.

\section{Acknowledgments}

Versions of this paper were presented at a department colloquium at the University of the Witwatersrand, at a meeting of the junior reading group at Institut Jean Nicod, and at a semantics seminar run by Philippe Schlenker. I would like to thank all of the participants at those presentations for their feedback. Thanks to Chris Barker, Manuel Križ, Murali Ramachandran, Daniel Rothschild and Yael Sharvit for helpful discussion of various points. Also, Ben Holguín, Ethan Nowak, James Pryor, Stephen Schiffer and Philippe Schlenker provided useful comments on earlier drafts. Finally, I would especially like to thank Cian Dorr for his continued encouragement, and for providing valuable feedback at every stage of the project's development. 


\section{References}

Abbott, Barbara. 2002. Donkey Demonstratives. Natural Language Semantics, $\mathbf{1 0}(4), 285-298$.

Anvari, Amir. 2018. Logical Integrity: from Maximize Presupposition! to Mismatching Implicatures. lingbuzz/003866.

Bach, Emmon, \& Cooper, Robin. 1978. The NP-S Analysis of Relative Clauses and Compositional Semantics. Linguistics and Philosophy, 2(1), 145-150.

Bhatt, Rajesh. 2002. The Raising Analysis of Relative Clauses: Evidence From Adjectival Modification. Natural Language Semantics, 10(1), 43-90.

Blumberg, Kyle. 2017. Ignorance Implicatures and Non-doxastic Attitude Verbs. Pages 135-145 of: Alexandre Cremers, Thom van Gessel, \& Roelofsen, Floris (eds), Proceedings of the 21st Amsterdam Colloquium.

Blumberg, Kyle. 2018. A note on deriving Minimize Restrictors! New York University.

Chemla, E. 2007. An Epistemic Step for Anti-Presuppositions. Journal of Semantics, 25(2), 141-173.

Coppock, Elizabeth, \& Beaver, David. 2012. Weak Uniqueness: The Only Difference Between Definites and Indefinites. Semantics and Linguistic Theory, $\mathbf{2 2}(0), 527-544$.

Coppock, Elizabeth, \& Beaver, David. 2015. Definiteness and Determinacy. Linguistics and Philosophy, 38(5), 377-435.

Dayal, Veneeta. 1998. "Any" as Inherently Modal. Linguistics and Philosophy, 21(5), 433-476.

Elbourne, Paul. 2005. Situations and Individuals. The MIT Press.

Elbourne, Paul. 2008. Demonstratives as Individual Concepts. Linguistics and Philosophy, 31(4), 409-466.

Elbourne, Paul. 2013. Definite Descriptions. OUP Oxford.

Fox, Danny. 2007. Presupposition and Implicature in Compositional Semantics. London: Palgrave Macmillan UK. Chap. Free Choice and the Theory of Scalar Implicatures, pages 71-120. 
Hawthorne, John, \& Manley, David. 2012. The Reference Book. Oxford University Press.

Heim, Irene. 1990. E-Type Pronouns and Donkey Anaphora. Linguistics and Philosophy, 13(2), 137-77.

Heim, Irene. 1991. Artikel und Definitheit. In: v. Stechow, A., \& Wunderlich, D. (eds), Handbuch der Semantik. Berlin: de Gruyter.

Heim, Irene, \& Kratzer, Angelika. 1998. Semantics in Generative Grammar. Blackwell.

Herdan, Simona, \& Sharvit, Yael. 2006. Definite and Nondefinite Superlatives and NPI Licensing. Syntax, 9(1), 1-31.

Kaplan, David. 1989. Demonstratives. Pages 481-563 of: Almog, Joseph, Perry, John, \& Wettstein, Howard (eds), Themes From Kaplan. Oxford University Press.

Katzir, Roni. 2007. Structurally-Defined Alternatives. Linguistics and Philosophy, 30(6), 669-690.

King, Jeffrey C. 2001. Complex Demonstratives: A Quantificational Account. MIT Press.

King, Jeffrey C., \& Lewis, Karen S. 2016. Anaphora. In: Zalta, Edward N. (ed), The Stanford Encyclopedia of Philosophy, summer 2016 edn. Metaphysics Research Lab, Stanford University.

Lakoff, Robin. 1974. Remarks on 'this' and 'that'. CLS.

Marty, Paul. 2017. Implicatures in the DP domain. Ph.D. thesis, MIT.

Mayr, Clemens, \& Romoli, Jacopo. 2016. A puzzle for theories of redundancy: Exhaustification, incrementality, and the notion of local context. Semantics and Pragmatics, 9(7), 1-48.

Mikkelsen, Line. 2004. Specifying Who: On the Structure,Meaning, and Use of Specificational Copular Clauses. Ph.D. thesis, University of California, Santa Cruz. 
Nowak, Ethan. 2014. Demonstratives Without Rigidity or Ambiguity. Linguistics and Philosophy, 37(5), 409-436.

Nowak, Ethan. 2015. Complex demonstratives, hidden arguments, and presupposition. Unpublished manuscript.

Nowak, Ethan. 2018. Saying 'that $F$ ' is saying which $F$ : complex demonstratives, hidden arguments, and presupposition. Unpublished manuscript.

Nunberg, Geoffrey. 1993. Indexicality and Deixis. Linguistics and Philosophy, 16(1), 1-43.

Percus, Orin. 2000. Constraints on Some Other Variables in Syntax. Natural Language Semantics, 8(3), 173-229.

Percus, Orin. 2006. Antipresuppositions. In: Ueyama, A. (ed), Theoretical and Empirical Studies of Reference and Anaphora: Toward the establishment of generative grammar as an empirical science.

Roberts, Craige. 2002. Demonstratives as Definites. Pages 89-196 of: van Deemter, K., \& Kibble, R. (eds), Information Sharing: Reference and Presupposition in Language Generation and Interpretation. CSLI Press.

Sauerland, Uli. 2004. Scalar Implicatures in Complex Sentences. Linguistics and Philosophy, 27(3), 367-391.

Schlenker, Philippe. 2005. Minimize Restrictors!(Notes on Definite Descriptions, Condition Cand Epithets). In: Maier, Emar, Bary, Corien, \& Huitink, Janneke (eds), Proceedings of Sub9.

Schlenker, Philippe. 2008. Be Articulate: A Pragmatic Theory of Presupposition Projection. Theoretical Linguistics, 34(3), 157-212.

Schlenker, Philippe. 2009. Local Contexts. Semantics and Pragmatics, 2(3), $1-78$.

Schlenker, Philippe. 2012. Maximize Presupposition and Gricean Reasoning. Natural Language Semantics, 20(4), 391-429.

Schoubye, Anders J. 2011. On Denoting. Ph.D. thesis, University of St Andrews. 
Sharvy, Richard. 1980. A More General Theory of Definite Descriptions. Philosophical Review, 89(4), 607-624.

Singh, Raj. 2011. Maximize Presupposition! and local contexts. Natural Language Semantics, 19(2), 149-168.

Soames, Scott. 1986. Incomplete Definite Descriptions. Notre Dame Journal of Formal Logic, 27(3), 349-375.

Stalnaker, Robert. 1978. Assertion. Syntax and Semantics (New York Academic Press), 9, 315-332.

Stanley, Jason, \& Szabó, Zoltan Gendler. 2000. On Quantifier Domain Restriction. Mind and Language, 15(2-3), 219-261.

Stanley, Jason C. 2002. Nominal Restriction. Pages 365-390 of: Peter, Georg, \& Preyer, Gerhard (eds), Logical Form and Language. Oxford University Press.

Westerståhl, Dag. 1985. Determiners and Context Sets. Pages 45-71 of: Generalized Quantifiers in Natural Language. Foris Publications.

Wolter, Lynsey. 2006. That's That: The Semantics and Pragmatics of Demonstrative Noun Phrases. Ph.D. thesis, University of California, Santa Cruz.

Yalcin, Seth. 2014. Semantics and Metasemantics in the Context of Generative Grammar. In: Burgess, Alexis, \& Sherman, Brett (eds), Metasemantics: New Essays on the Foundations of Meaning. Oxford University Press. 